\title{
Effects of Particle Properties on Visualizing Flows in a Two- Stage Electrostatic Precipitator Using Particle Image Velocimetry
}

\author{
Gede Suantara Darma and Wei-Hsin TIEN ${ }^{1}$ \\ ${ }^{1}$ Department of Mechanical Engineering, National Taiwan University of Science and \\ Technology, Taipei, Taiwan \\ whtien@mail.ntust.edu.tw
}

\begin{abstract}
The amount of particulate matter (PM) in the environment has been confirmed to be health risks on human bodies[1, 2], and therefore removing suspended particles has become the research goal of many studies. Electrostatic precipitator (ESP) is one of the high-efficiency particle collection technologies[3-7]. Particle Image Velocimetry (PIV) has been an effective tool for visualizing the flow patterns in experimental fluid mechanics, and many studies adopted this technique to study flows in ESP[8-10]. However, particles charged by the electric field can cause deviation in measurement results since it does not follow the ionized air flow which can be charged differently from the tracer particles. In this study, the observation of the effects of different particle properties on flow field in a two-stage ESP is the objectives of this study. A two-stage ESP was built and four different seeding particles, aluminum oxide $\left(\mathrm{Al}_{2} \mathrm{O}_{3}\right)$ particle, oil droplet particle, sodium chloride $(\mathrm{NaCl})$ particle, and titanium dioxide $\left(\mathrm{TiO}_{2}\right)$ particle, are tested in the current study. In this study, the streamwise velocity of the flows ranges from $2.36 \mathrm{~m} / \mathrm{s}$ to $4.18 \mathrm{~m} / \mathrm{s}$, the voltage of the corona electrode varies from $8 \mathrm{kV}$ to $12 \mathrm{kV}$ with a positive polarity, and the voltage of the collector electrode is fixed at $16 \mathrm{kV}$. To investigate the 3-D flow patterns inside the channel, data at different planes were taken for comparison. The results show that by increasing charge voltage from $8 \mathrm{kV}$ to $12 \mathrm{kV}$ with a streamwise flow velocity the $2.36 \mathrm{~m} / \mathrm{s}$, the y-component velocity for $\mathrm{Al}_{2} \mathrm{O}_{3}$ particle, oil droplet particle, $\mathrm{NaCl}$ particle and $\mathrm{TiO}_{2}$ particle increased by $50.6 \%, 76.0 \%, 33.5 \%$ and $51.9 \%$, respectively. Moreover, for the case of the $4.18 \mathrm{~m} / \mathrm{s}$ primary flow, the y-component velocity for $\mathrm{Al}_{2} \mathrm{O}_{3}$ particle, oil droplet particle, $\mathrm{NaCl}$ particle and $\mathrm{TiO}_{2}$ particle increase by $52.7 \%, 59.2 \%, 59.4 \%$ and $65.9 \%$ after the voltages increase from $8 \mathrm{kV}$ to $12 \mathrm{kV}$. PIV results for oil droplet particle shows slower y-component velocities, which can be due to the lower Archimedes number of 3.12E-06 and the mobility number that is larger than 3 . On the contrary, in most of results from $\mathrm{TiO}_{2}$ particles show high y-component velocity, which is due to the highest Archimedes number of $1.15 \mathrm{E}-03$ of the seeding particles tested in this study. This result shows that the particle is less affected by buoyancy effect. The PIV results of the middle plane also shows that the ycomponent of velocity from $-2.6 \mathrm{~m} / \mathrm{s}$ to $-0.5 \mathrm{~m} / \mathrm{s}$, in contrast to $-1.0 \mathrm{~m} / \mathrm{s}$ to $1.0 \mathrm{~m} / \mathrm{s}$ from the near wall observation plane. These results are consistent to simulation results of the electric field distribution, which shows unequal electric field strengths between the middle and near wall regions of the test section. Only half of the cage shape distribution of the electric field can be observed, and primary flow influences the ionic wind to move to the downstream area. Based on the results, the oil droplet and $\mathrm{TiO}_{2}$ particles are more suitable for the role of tracer particles compared to aluminum oxide and sodium chloride particles.
\end{abstract}

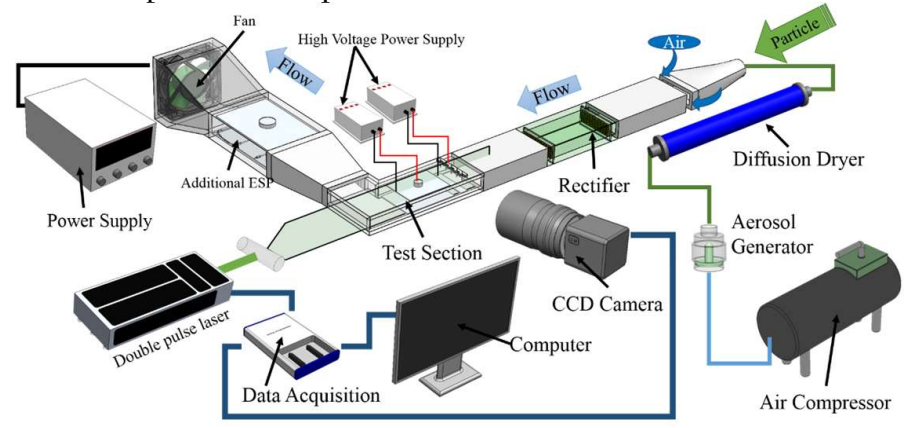

Figure 1 Schematic Diagram Two-stage ESP 
(A)

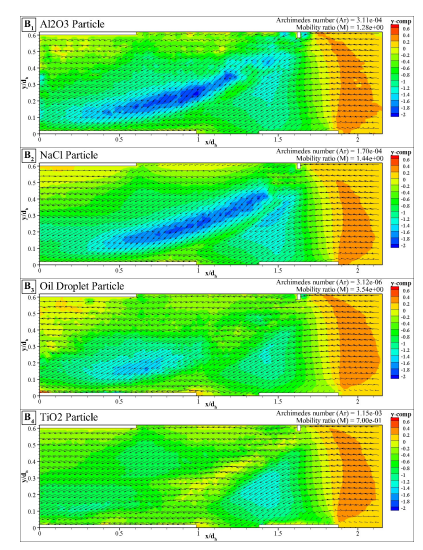

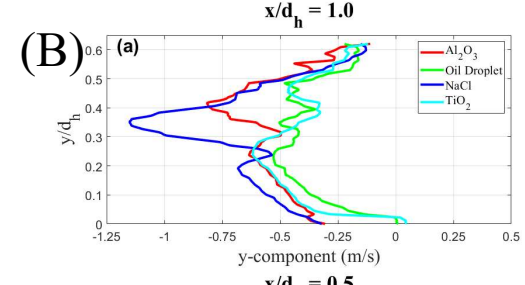
$\mathrm{x} / \mathrm{d}_{\mathrm{h}}=0.5$

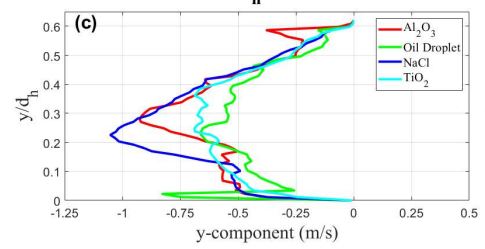

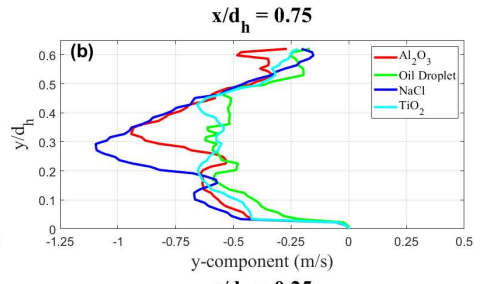
$\mathrm{x} / \mathrm{d}_{\mathrm{h}}=\mathbf{0 . 2 5}$

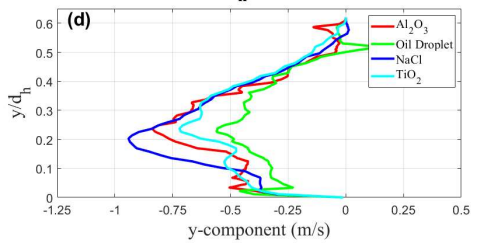

Figure 2 PIV results at $2.63 \mathrm{~m} / \mathrm{s}$ primary flow with $8 \mathrm{kV}$ charge and $16 \mathrm{kV}$ collector: (A) velocity maps of four different particles, and (B) velocity profiles at four different locations: (a) $\mathrm{X} / \mathrm{d}_{\mathrm{h}}=0.25$, (b) $\mathrm{X} / \mathrm{d}_{\mathrm{h}}=0.5$,

(c) $\mathrm{X} / \mathrm{d}_{\mathrm{h}}=0.75$ and (d) $\mathrm{X} / \mathrm{d}_{\mathrm{h}}=1.0$

\section{References}

[1] F. Sánchez-Soberón et al., "Main components and human health risks assessment of PM10, PM2. 5, and PM1 in two areas influenced by cement plants," Atmospheric Environment, vol. 120, pp. 109-116, 2015.

[2] J. T. Zelikoff et al., "Effects of inhaled ambient particulate matter on pulmonary antimicrobial immune defense," Inhalation Toxicology, vol. 15, no. 2, pp. 131-150, 2003.

[3] H. J. White, Industrial electrostatic precipitation. Addison-Wesley Pub. Co., 1963.

[4] J. Böhm, Electrostatic precipitators. Elsevier Amsterdam, 1982.

[5] S. Masuda and S. Hosokawa, "Electrostatic precipitation," in Handbook of electrostatic processes: Marcel Dekker New York, 1995, pp. 441-480.

[6] A. Mizuno, "Electrostatic precipitation," IEEE Transactions on Dielectrics and Electrical Insulation, vol. 7, no. 5, pp. 615-624, 2000.

[7] Z. He and E. M. Dass, "Correlation of design parameters with performance for electrostatic precipitator. Part II. Design of experiment based on 3D FEM simulation," Applied Mathematical Modelling, vol. 57, pp. 656-669, 2018.

[8] J. Podliński, M. Kocik, R. Barbucha, A. Niewulis, J. Mizeraczyk, and A. Mizuno, "3D PIV measurements of the EHD flow patterns in a narrow lectrostatic precipitator with wire-plate or wireflocking electrodes," Czechoslovak Journal of Physics, vol. 56, pp. B1009-B1016, 10/01 2006.

[9] A. Niewulis, J. Podliński, M. Kocik, R. Barbucha, J. Mizeraczyk, and A. Mizuno, "EHD flow measured by 3D PIV in a narrow electrostatic precipitator with longitudinal-to-flow wire electrode and smooth or flocking grounded plane electrode," Journal of Electrostatics, vol. 65, no. 12, pp. 728-734, 2007/11/01/ 2007.

[10] C. Wang, Z. Xie, B. Xu, J. Li, and X. Zhou, "Experimental Study on EHD Flow Transition in a Small Scale Wire-plate ESP," Measurement Science Review, vol. 16, 06/01 2016. 